\title{
A Bridge Too Far? The Staten Island/ Hudson-Bergen Light Rail Missed Connection
}

\author{
Cameron E. Gordon, Ph.D., University of Canberra (Australia) \\ Bukurije Bajrami, Nóra Tábori Santiago, Jonathan Peters, Ph.D. \\ City University of New York/College of Staten Island
}

\begin{abstract}
Few urban areas are as economically and socially integrated as the New York City borough of Staten Island and the New Jersey communities of Bayonne and Jersey City just across the Hudson River. These strong links are illustrated by travel patterns across a north-south corridor from Staten Island up into Bayonne. Yet transit planning and development policy and implementation have been radically different in the two areas, with slow and, right now, stunted development of transit in Staten Island, New York City, as contrasted with the muscular and systematic approach taken in Bayonne and Jersey City, New Jersey. This paper analyzes the links between the two areas, describes the different transit policies taken in each, assesses the outcomes of these different policies, and offers suggestions for ways in which transit and development links could be improved, in particular an extension of the HudsonBergen Light Rail (HBLR) into Staten Island. The paper also discusses the interim use of buses as a pre-development phase for light rail (LRT) or bus rapid transit (BRT), focusing on the relatively new 589 route in Staten Island that now links directly to the $H B L R$ and which immediately attracted strong ridership.
\end{abstract}




\section{Introduction}

Economic development of dense urban areas requires effective mass transit planning. Such planning is driven by institutions, and the way these function can make all the difference in the way such plans are developed and implemented. A striking example of this can be seen in two communities that are close geographic, economic, and social neighbors, yet have strikingly different transit configurations with strikingly different results: the borough of Staten Island, New York, and neighboring Bayonne and Jersey City, New Jersey. Staten Island has a transit system almost entirely built around buses, while Bayonne and Jersey City have developed a multimodal system containing integrated light rail (LRT), heavy rail, and buses. Their economic outcomes are also strikingly different. While both are prosperous in terms of income, Bayonne and especially Jersey City have developed a far more diverse and high-quality job base. Staten Island remains primarily a "bedroom" community for people commuting to jobs elsewhere.

This paper analyzes the links between the two areas, describes the different transit policies taken in each, assesses the outcomes of these different policies, and offers suggestions for ways in which transit and development links could be improved, in particular an extension of the Hudson-Bergen Light Rail (HBLR) into Staten Island. The paper also discusses the interim use of buses as a pre-development phase for LRT or bus rapid transit (BRT), focusing on the relatively new S89 route in Staten Island that now directly links to the HBLR and which immediately attracted strong ridership. The overall analysis is grounded on a brief review of the relevant literature on transit planning, policy, and economic development.

\section{Mass Transit Planning in Dense Urban Areas}

Large, dense cities must have some sort of transit system. The densities of population and economic activity in such areas are high enough to support a viable patronage, and the costs of not having transit, in terms of congestion, pollution, and other negative externalities provide additional justification and are imperative. There are also clear positive synergies in the form of direct effects on land value and the opening of desirable locations for social and economic activity.

Having transit does not, however, solve the question of what a system should look like, how it should evolve, and what technologies it should use. There are many examples of urban transit that have costs that appear to outweigh the benefits, at least in the short- and medium terms. Moreover, there are significant lags between costs and benefits, and some technologies, especially LRT and heavy-rail 
transit (HRT), have substantial capital costs that may take years or even decades to recover. As budgetary resources are always scarce, system design and phasing are critical to ensure that a useful and beneficial system is ultimately built, even if in phases.

A number of clear principles have emerged from the literature on general transit planning for urban areas with sufficient density. Transit multimodality is a foundational principle. In other words, municipalities need to employ a portfolio of transit technologies to meet the diverse needs and conditions presented by a given service area. In transit, these technologies are, generically speaking, bus, BRT, LRT, and heavy rail (HRT), with each category having multiple specific forms (Brown and Thompson 2009).

Following from this is the notion that technology (generally) should fit the need rather than being imposed on an area and hoping for the best. HRT is excellent for some requirements, such as commuter travel between dense nodes, but less desirable for service in more spread out and less dense areas, where buses are often most economical and appropriate. Some systems, like LRT, require dedicated rights-ofway (ROW) that might not be available, or are perhaps inconsistently available. Often, multimodal mixed systems work best-for example, an LRT employing ROW where available and then transitioning to a bus where it is not. BRT is a good example of technology that can be especially flexible, with buses using dedicated busways where possible and then moving on to regular roads where necessary. The Silver Line in Boston is an example of this (Hensher 2007).

Routing and phasing of transit is another key issue. Patterns of residential and commercial activity across an urban space and across a time period will dictate what type of service should be provided, how frequent it is, and where it should go. Urban areas have become increasingly multi-destination, and trips have become increasingly multi-purpose, militating against the traditional peak/off-peak CBDto-suburb configurations that were the standard 50 years ago and which many systems (including New York City's) still largely focus on today. Use of a variety of technologies and across a variety of schedules and deployments can be especially effective in adapting existing infrastructure to changing conditions (Schumann 2006).

Transit investment also can yield what Paul Mees calls the "network effect" even in the midst of low density and auto-based development. As Mees puts it, "Public transit (can) imitate the flexibility of the car by knitting different routes into a single multi-modal network. Making transfers between the different routes near 
effortless enables the public transit network to mimic the "go anywhere, anytime" flexibility of a road system (Mees 2010, 8).

It is, of course, very important to meet current needs effectively. But it is also important to guide development through transit investment as well. There is certainly risk in such planning, especially of "white elephants," but future land uses cannot be simply left to chance with transit following in response. Risk and expense can be minimized in some cases by taking an "incremental" approach, developing or testing demand with buses first, then following with more capital-intensive transit such as BRT and LRT (Hensher 2007).

There are many benefits to getting transit right. By improving the public transportation system through the efficient use of transit technology, emissions are dramatically reduced, traffic congestion is relieved, and riders are provided with a reliable source of commuter service. Here again, the principles above come into play. "LRT stations need to be focal points of multimodalism" (Sungyop et al. 2007, 513), says one author, and this is not just true of LRT but also of BRT and, in some cases such as large transit exchanges, buses as well.

\section{The Tale of Two Cities: Staten Island and Bayonne/Jersey City}

An interesting sort of "natural experiment" on the effect on planning and policy on travel and economic development outcomes is occurring in the New York City area where one part of the city-the borough of Staten Island-has radically different transit policies and radically different outcomes than two communities just across the river, Bayonne and Jersey City, New Jersey. Bayonne, in particular, is less than a mile away from Port Richmond, Staten Island, and both communities were in similar places developmentally 40 years ago, but are now in very different places today, the main difference being public transport policy. It is, therefore, interesting to compare these two communities.

New York City has the highest transit usage rate in the United States. Yet many communities within New York City are underserved by public transit, especially for many of the four out of five New Yorkers who live outside the borough of Manhattan. Staten Island, in particular, has had a large increase in population growth, which has resulted in huge increases in travel; however, no major adjustments have been made to deal with that expansion.

Staten Island population reached 444,000 in 2000 and 470,000 in 2005 and is projected to reach a new height of 552,000 in 2030 -a 24.4 percent growth rate 
increase, the highest in any borough (Fitzsimmons and Birch 2009). However, this estimate is lower than one provided by the U.S. Census indicating that Staten Island's population will reach 630,000 by 2030 (Cornell university 2008).

Yet there is a lack of general transit service in Staten Island because of the spatial imbalance between activity centers and transit infrastructure. Population growth in Staten Island has been prodigious, but transit planning to either guide or respond to that growth has been almost nonexistent. The system, which is primarily run on local and express buses, has not adapted to growth, nor does it serve a majority of the citizens who have to rely on automobile usage, thus causing traffic congestion.

Across the river from Staten Island in New Jersey are Bayonne and its neighbor, Jersey City. In the 1960s and 1970s, these once booming industrial communities became derelict in an era of post-industrialization. But, unlike Staten Island, Jersey City had a good rail connection to Manhattan via the Port Authority TransHudson (PATH) line (and HRT line), as well as a dense cluster of New Jersey Transit (NJT) commuter trains. As Manhattan's financial district boomed, Jersey City took advantage of this transit connection to actively lure the financial "back office" to a Gold Coast along the Hudson River that now bristles with high-rise buildings and expensive condominiums. There was also a movement of artists to Jersey City from Manhattan and the other boroughs, taking advantage of cheaper rents on the other side of the Hudson and easy transit access to the cultural amenities of New York City (Fitzsimmons and Birch 2009).

The fact that both Staten Island and Jersey City are roughly equidistant from Wall Street yet Jersey City has all the back-office operations says much about the power of development policy and transit infrastructure. The story becomes even more interesting when considering Bayonne. Bayonne did not initially share in the Jersey City boom. At the time, it had no good transit links to Jersey City and none to Manhattan. Its relative distance and isolation caused it to remain in the economic doldrums, despite offering much cheaper real estate. In this sense, Bayonne's economic condition closely mirrored the downtrodden Port Richmond neighborhood in Staten Island that was a mere mile away across the Kill Van Kull and which suffered from similar transit neglect. Figure 1 shows the geographic proximity of these two communities along with the rail infrastructure that existed in both places in the 1950s. 


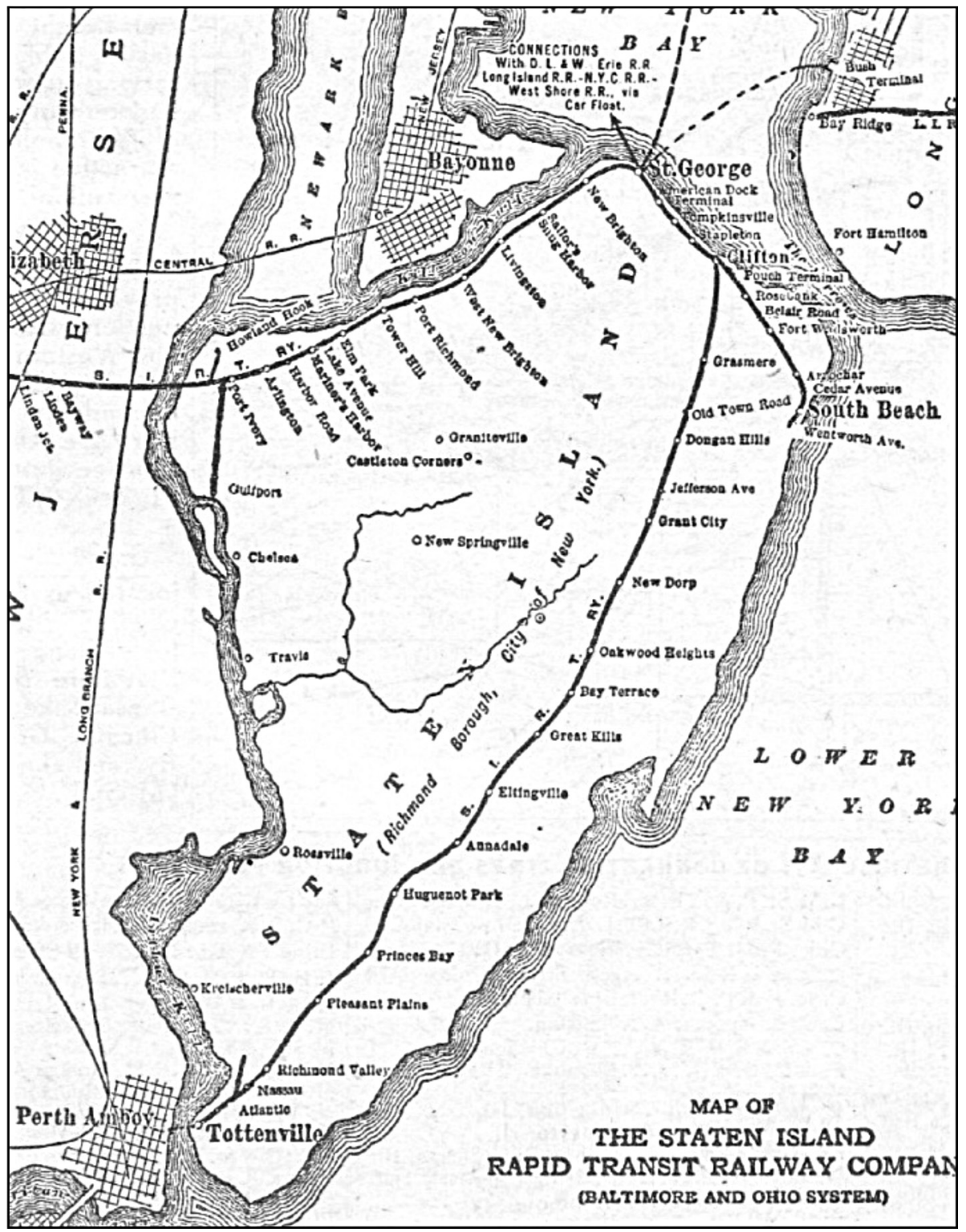

Figure 1. Passenger rail service in 1950s Staten Island, NY 


\section{The Hudson Bergen Light Rail}

New Jersey was proactive about Bayonne in a way that Staten Island has not been about its own transit-isolated communities (or, more properly speaking, New York City was, since Staten Island does not have independent planning authority and must work through city-wide institutions). The State of New Jersey decided to build the Hudson Bergen Light Rail (HBLR) to connect Bayonne with Jersey City and Hoboken and, through those communities, link the city with the wider metropolitan transit system. The HBLR began operation on a former freight rail easement in 2000, and a spur line to the West Side Avenue in Jersey City was added shortly afterwards. By 2002, service was extended to Hoboken Terminal. Service was than extended south to 22nd Street and north to Weehawken and to Union City in North Bergen.

The newest addition to the system is the elevated 8th Street station in Bayonne. Figure 3 shows this network and also shows the proximity of the end of this network to Staten Island. (Fitzsimmons and Birch 2009).

Ridership on this service has shown increasing numbers. The HBLR 20.6-mile light rail system operates with 23 stops and a daily ridership of 38,200 on a normal weekday. To eliminate the need to change between stations, the trains operate on three routes: West Side Avenue (Jersey City)-Tonnelle Avenue (North Bergen), Hoboken Terminal-Tonnelle Avenue (North Bergen), and 22nd Street (Bayonne)-Hoboken Terminal. Trains operate 5:00-1:00 AM daily, running every 5 minutes during the peak period within the core of the system. Off-peak operation during a weekday is every 5-10 minutes (NJT 2010).

The economic development benefits have been pronounced as well. Development has obviously been most pronounced in Jersey City, but Bayonne has gone from no commercial development to 626,270 square feet approved and proposed (by 2003/2004), while other nearby communities of similar size and character in Hudson County (Guttenberg, Harrison, and Kearny) had none (Fitzsimmons and Birch 2009). For Bayonne, these effects can be said to be at least partly driven by the $\mathrm{HBLR}$, which is the primary transit in the area. 


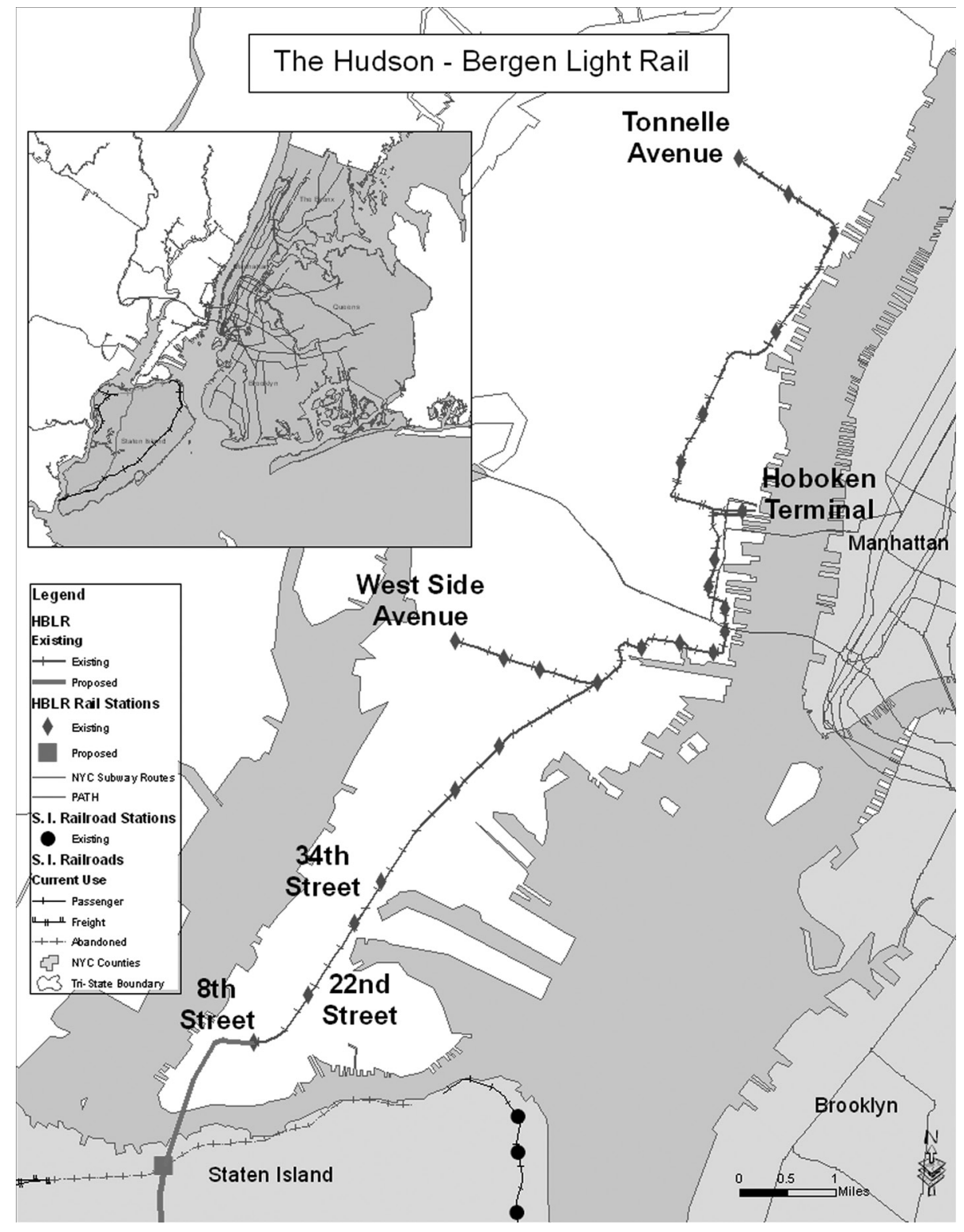

Figure 2. Map showing full HBLR system, current SIRT, and proposed connection 


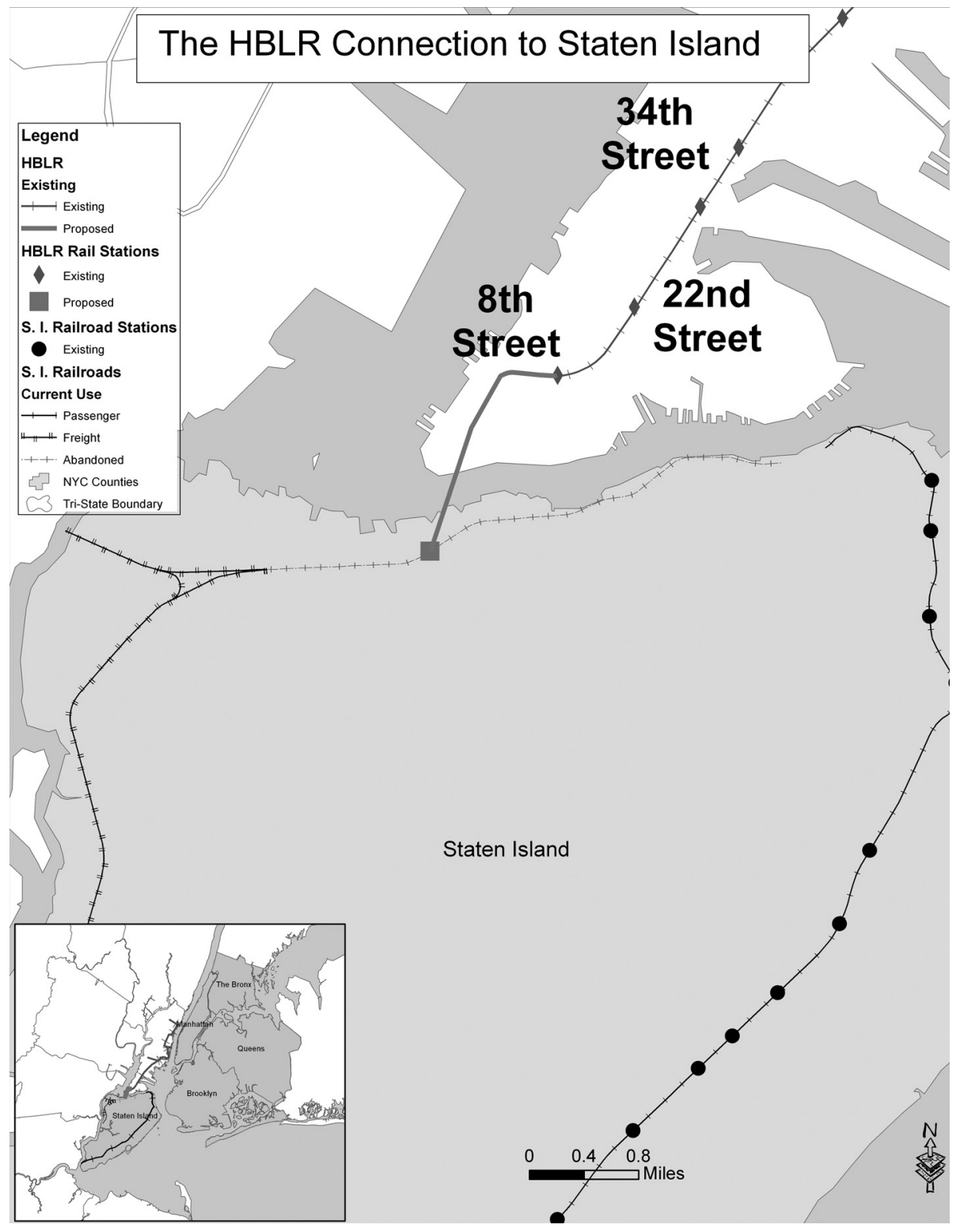

Figure 3. Map of proposed connection from Bayonne to Staten Island 


\section{Light Rail Transit as a Gap-Filling Mode}

LRT is quite often a "gap-filler" for existing transit, filling in holes in bus or rail service or extending the reach of those modes. U.S. statistics show that approximately 53.8 percent of light rail passengers drive and park at an LRT station, while 28.7 percent use bus as their mode of transit (9.1\% are picked up/dropped off and $8.4 \%$ walk to the station) (Sungyop et al. 2007). A total of 72.5 percent use LRT for a portion of their travel to and from school/work. This fits in with Mees' "network effect" concept as well, with different modes serving different needs but all being seamlessly linked to deliver trip flexibility.

The boroughs of New York City are an interesting case in this regard. There is a dense subway and commuter rail network, but outside of Manhattan (and even in a few areas in Manhattan), there are significant gaps which are infeasible, economically or practically, to fill with more HRT and yet which would be poorly served in many cases by traditional buses.

Table 1 shows the population distribution around train stations in NYC. The boroughs, Staten Island especially, are not well served by existing HRT infrastructure. Traditional bus service is not filling that gap well either. "Between 1970 and 2000, many of our greatest areas of growth have been underserved NY transit" (NYC 2011). According to U.S. Census 2010 data, only 26 percent of Staten Islanders lived within $1 / 2$ mile of the subway routes, compared to 94 percent of Manhattan residents (U.S. Census 2010).

\section{Table 1. Population of New York City Boroughs Census Tract Centroids within $1 / 2$-Mile Radius of Subway Routes}

\begin{tabular}{|c|c|c|c|}
\hline $\begin{array}{c}\text { NYC } \\
\text { Boroughs }\end{array}$ & $\begin{array}{c}1 / 2-\text { Mile Buffer Around } \\
\text { Subway Routes }\end{array}$ & $\begin{array}{c}\text { 2010 Census } \\
\text { Total Population }\end{array}$ & $\begin{array}{c}\text { Percentage of Population within } \\
\text { 1/2 Mile of Subway Routes }\end{array}$ \\
\hline Bronx & 998,729 & $1,385,108$ & $72 \%$ \\
\hline Brooklyn & $2,005,616$ & $2,504,700$ & $80 \%$ \\
\hline Manhattan & $1,489,979$ & $1,585,873$ & $94 \%$ \\
\hline Queens & $1,053,952$ & $2,230,722$ & $47 \%$ \\
\hline Staten Island & 120,753 & 468,730 & $26 \%$ \\
\hline
\end{tabular}

As Table 2 shows, the rate of automobile ownership on Staten Island is much higher than in the rest of the city. A total of 15.7 percent of Staten Island households do not own a vehicle, 37 percent own one vehicle, and the remaining 47 percent of households have two or more vehicles (U.S. Census 2006-2010 American Community Survey 5-Year Estimates). This situation, a result of poor transit availability, is replicated, if not as severely, in the other boroughs. 


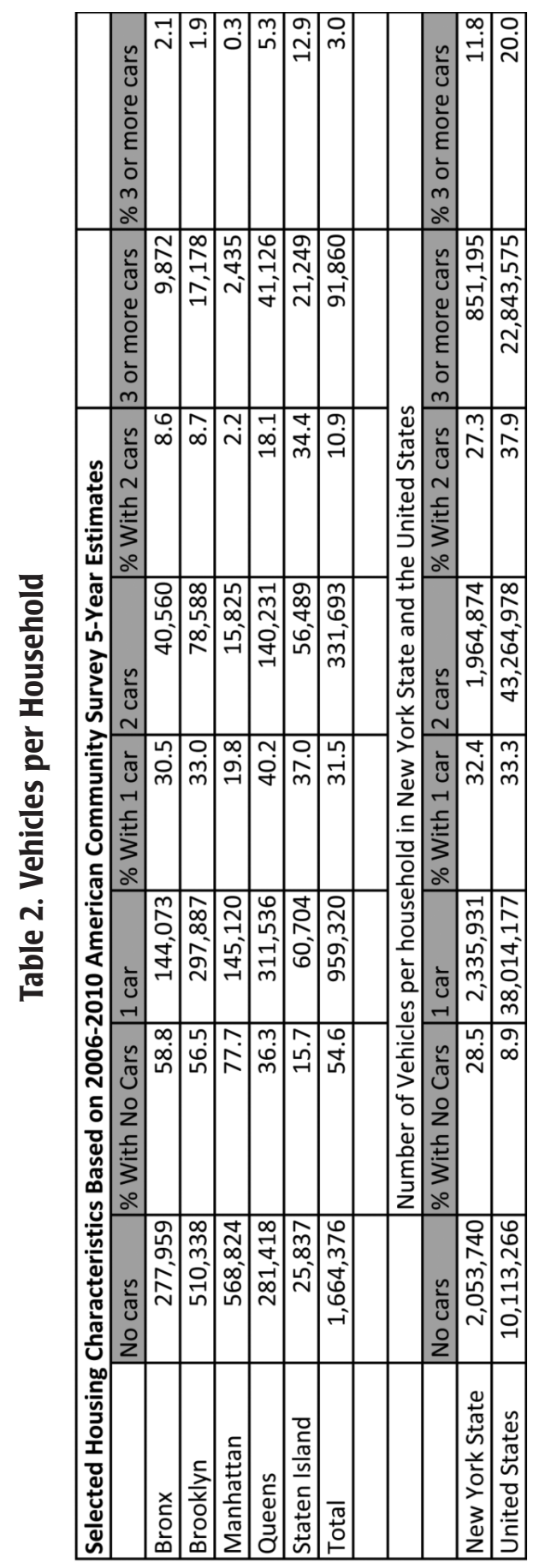




\section{A Mere Mile: The Case for a Staten Island/HBLR Link}

Bayonne was in a similar, perhaps worse, position than Staten Island back in the 1970s. NJ Transit planned and then built the HBLR, significantly ameliorating the transit gap within New Jersey and increasing connectivity with the dense and, before the LRT, inaccessible State transit system nearby.

Staten Island is less than two miles of road and bridge away from being connected to the HBLR. If such a connection were built, it would provide Staten Island with access to a regional national transportation infrastructure. Measurement from the proposed terminus station in Staten Island to the currently-under-construction 8th Street station of the HBLR is about $3 \mathrm{~km}(1.88 \mathrm{mi})$. LRT "gives medium-sized urban centers the chance to create direct links between inner city, the outlying districts and surrounding population centres" (De Bruijn and Veeneman 2009, 351). Staten Island residents currently have the longest commute (by any mode) in the nation and the most extreme commuters (i.e., those with work trips above 90 minutes long in either direction), and an LRT link would ameliorate this situation.

Based upon a discussion with NJ Transit, the estimated cost of construction is $\$ 150$ million dollars. New federal infrastructure is typically funded with 80 percent federal money and 20 percent local funding. This extension would include approximately 1.6 miles of track and could be expected to yield a probable ridership of 15,000 per weekday, which is actually the recommended HRT threshold for U.S. federal funding (the LRT threshold is 7,500). Still, these are forward estimates. Would actual ridership be that high if an LRT link between Staten Island and Bayonne was built? Fortunately, there is a good evidence to indicate a high probability of "yes."

\section{Hudson Bergen Light Rail and Buses as a Market Test}

Staten Island is linked to Bayonne by the Bayonne Bridge. When the Bayonne Bridge was built in 1931, sections of the roadway deck were reserved to accommodate heavy rail tracks (PANYNJ 2012). Some sort of rail transit was contemplated but, like many infrastructure projects of the era, the Great Depression literally derailed it.

Decades later, New Jersey's building of the HBLR on its side of the Bayonne Bridge has fulfilled a part of the original plan. The 8th Avenue station of that line is already built as an elevated station, so the infrastructure will mostly be in place for the extension of the service through the Bayonne Bridge should that be decided.

The market potential of more robust transit linkage between Staten Island and Bayonne has been effectively "empirically" tested through initial bus service along 
a potential LRT corridor in Staten Island that could form the basic spine of a connecting service to the HBLR. In 2007, the Metropolitan Transit Authority (MTA) established a bus route, S89, to link Staten Island with the HBLR. The S89 route begins at Richmond Avenue and Hylan Boulevard and completes its route at the 34th Street HBLR Station. However, this bus line only currently operates in peak $A M$ and $P M$ hours on weekdays and has no weekend service. In spite of these limitations, this bus route has shown that there are a promising number of commuters who depend on this daily service and also what an approximate viable alignment for a Staten Island LRT line could be.

Figure 4 shows the $\mathrm{S} 89$ boardings in both directions. These loading counts show that the $\mathrm{S} 89$ has generated a strong and immediate ridership on a daily basis that is relatively broadly distributed, particularly along the northern half of the route. The " 0 " at the Northbound HBLR station indicates that everyone exits the bus at this stop; the " 0 " in the Southbound 589 bus station indicates the last 889 service stop.

What is generating this ridership? In a few words: the connection to the HBLR. The MTA reports that in 2009 S89 annual ridership was 233,067 , with a daily average weekday ridership of 918 (Schumann 2006). According to a NJ Transit report conducted by Rutgers University, this service provides 800-900 NY riders per weekday that ride the HBLR (Robins and Jans 2008). These riders are almost entirely heading to and from the LRT in Bayonne. As of 2011, annual ridership was 224,071, a 1.2 percent increase from 2010's annual ridership of 221,507.

This is confirmed by other data. A license plate survey was conducted on June 14, 2010, at the HBLR 34th Street Station parking lot by researchers from the College of Staten Island. A total of 424 cars were parked at this facility, and all of the vehicles were recorded and counted by the authors. This vehicle count showed that 70 percent of the vehicles outside the LRT station belonged to residents of New York, 28 percent were from New Jersey, and the remaining 3 percent were from other states. Based upon a cross-reference from the NYC Department of Motor Vehicles database, 207 of the license plates were from NY State, with 198 of these from Staten Island. 


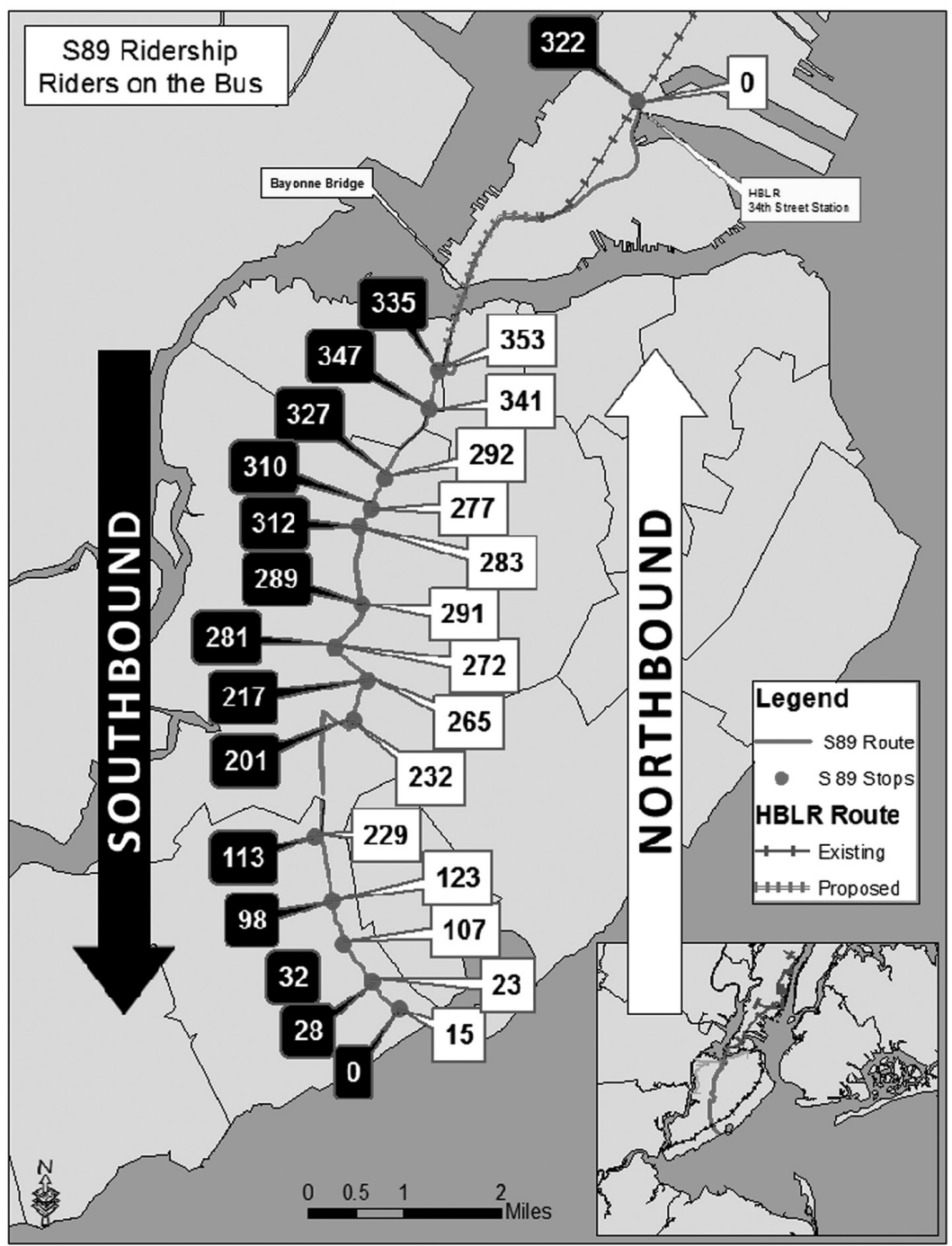

Figure 4. Map showing ridership on S89 bus in both northbound and southbound directions (numbers indicate how many riders are on bus at each stop)

Figure 5 shows in detail the distribution of theses license plates by ZIP code. This broadly confirms results of the HBLR study by Marchwinski et al. (1999), the results of which are depicted in Figure 6). Based on the survey data conducted by both the College of Staten Island/NYS DMV and the NJ Transit HBLR report, 90 percent of the license plates belonged to Staten Islanders. The annual usage rates for Staten 
Island riders were expected to be at 281,060 riders, based on 353 Northbound and 322 Southbound riders on the 589 during a standard 260 business day year and the 198 recorded parked vehicles belonging to Staten Islanders driving both to and from the station.

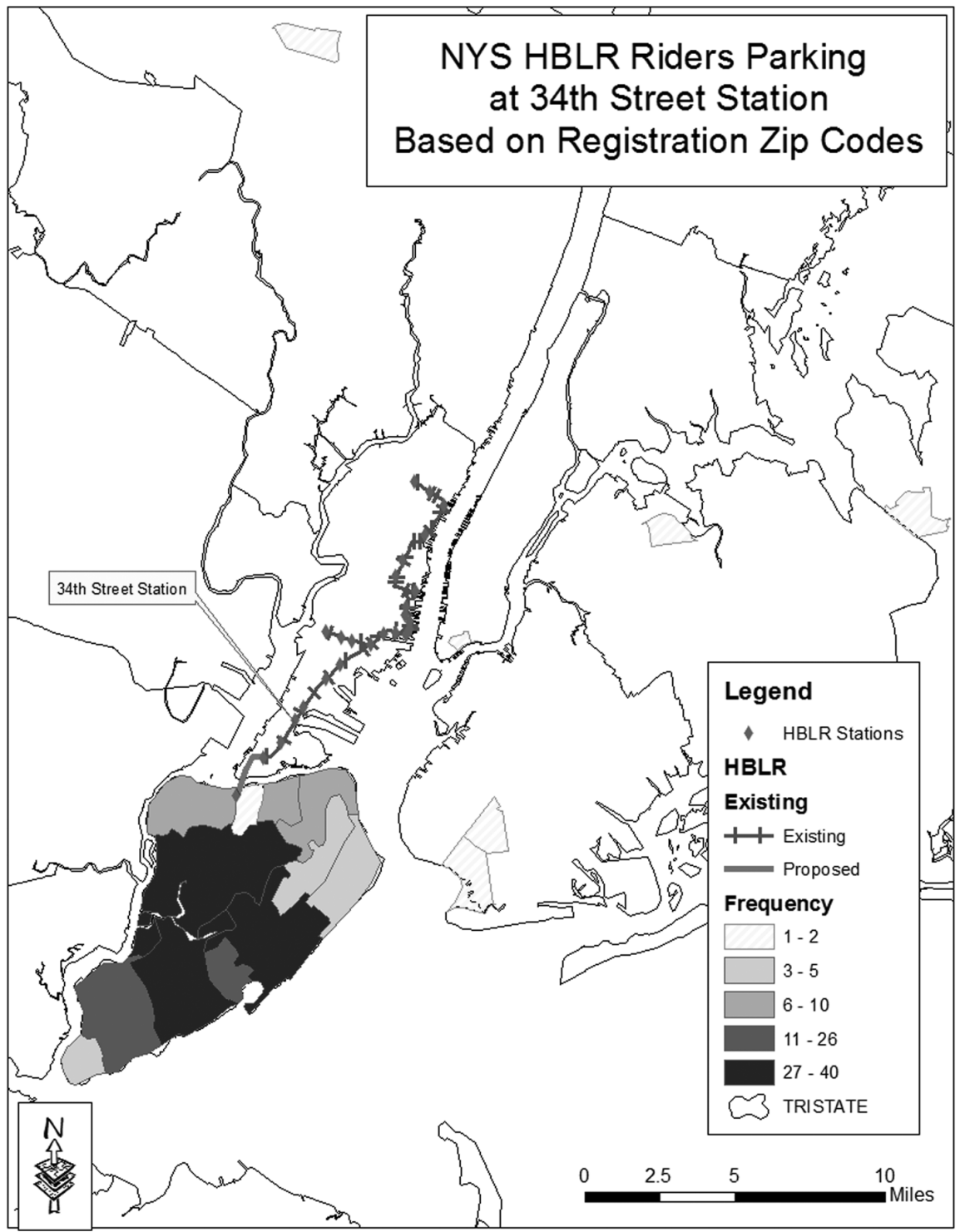

Figure 5. HBLR Staten Island riders by ZIP code based on CSI's 2010 HBLR 34th Street survey 


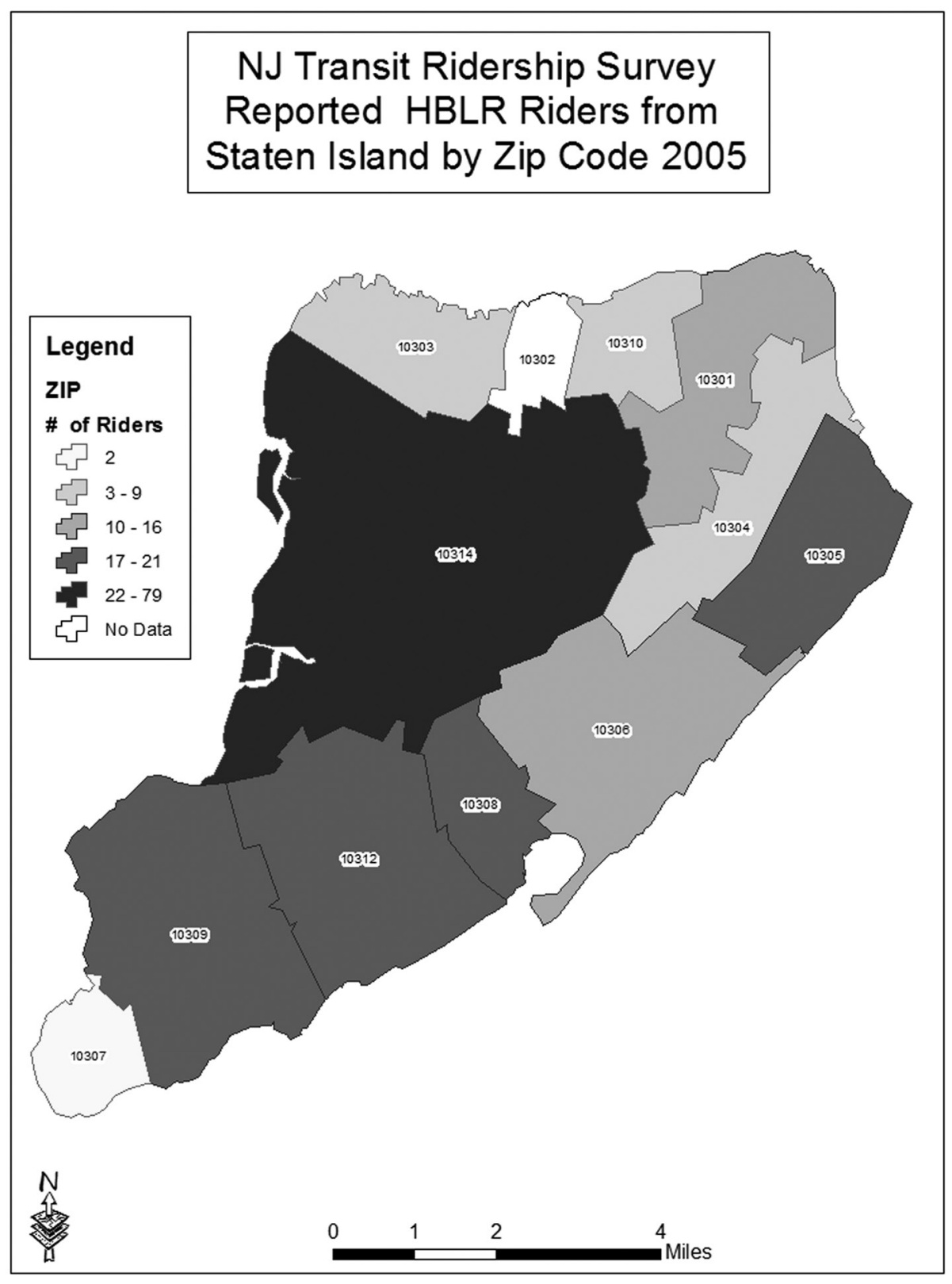

Figure 6. Map illustrating 2005 Ridership Survey conducted by NJ Transit 
There is strong reason to believe that ridership on an LRT would be much greater than that of the current S89. The S89 is limited to people who live within walking distance of the route or those who transfer from a local bus to the S89 or park on the street. These riders are forced to take a minimum of two to three modes (walk, bus) of transport prior to arriving at the HBLR station. Even so, ridership has been strong. The creation of an LRT integrated with the HBLR would certainly increase both ridership and connectivity.

Another limit currently is that the $\mathbf{S} 89$ service provides access only to residents in close proximity of Richmond Avenue, with the rest of Staten Island underserved by any public transportation going to or from the HBLR. Frequency of service is also limited: this is a peak-only period service, running inbound (to NJ) from 5:25-8:22 AM and outbound (to SI) 3:55-7:25 PM. Increasing service frequency and connectivity through an LRT would deliver significant advantages to riders and likely significantly increase transit usage.

According to NY Transit's report from April 2008, the "HBLR has been successful in reducing peak period auto trips from Bayonne and Staten Island to downtown Jersey City employment centers" (PANYNJ 2012).

\section{Rail Transit Access and Non-Auto Households}

One of the more interesting questions in transportation is the impact of transit services on auto ownership and the frequency of non-car-owning households. The authors examined the five counties of New York City to observe the relationship between household proximity to the New York heavy rail system and non-carowning households using Geographic Information System (GIS) mapping of the 2010 Census data on automobile ownership and overlaying that with the New York City Heavy Rail Network (New York City Subway and Staten Island Railroad). Figure 7 provides an overview of that data.

The authors then selected the Census tracts that were within $1 / 2$ mile of the heavy rail network and then calculated the number of households without cars and divided it by total households within that zone. We also calculated the share of no-car households in the areas outside of the heavy rail network. Based on this, we were able to calculate the conditional probability of a household living within $1 / 2$ mile of the rail network given that they are zero-car households. 
Journal of Public Transportation, Vol. 16, No. 3, 2013

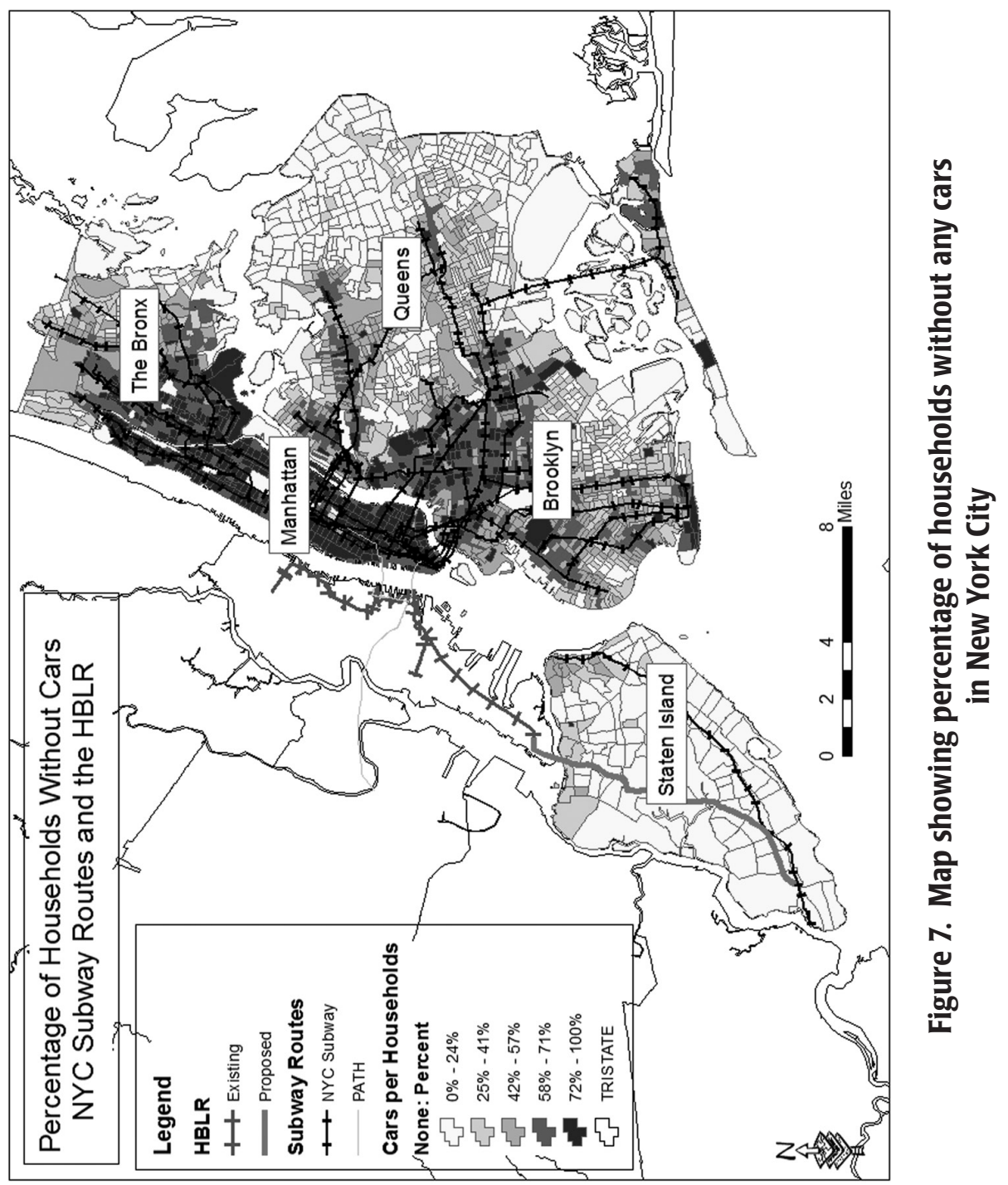




\section{Table 2. NYC Actual Rates and Relative Rates of Zero-Car Households}

\begin{tabular}{|l|c|c|}
\hline Characteristic & Rate & Relative Rate \\
\hline Within $1 \frac{2}{2}$ mile of subway line & $42.73 \%$ & $85.83 \%$ \\
\hline Outside $1 \frac{1}{2}$ mile of subway line & $7.05 \%$ & $14.17 \%$ \\
\hline Total & $49.78 \%$ & \\
\hline
\end{tabular}

It was found that 85 percent of households that did not own are car were within $1 / 2$ mile of a heavy rail line. In New York City, while the overall percentage of households within $1 / 2$ mile of the subway and rail system is very high (74.7\%), the zero-car households tended to be even more concentrated. We found the exact opposite in terms of households with automobiles - they tended to be more likely to live outside of the $1 / 2$-mile range of the heavy rail system. These results confirm the potential benefit of rail transit as a density magnet as well as supporting non-automobile households in a dense urban setting.

We estimate that the combination of a lower-density of transit network in regions outside of Manhattan creates the potential need for an additional 266,082 vehicles in New York City. In addition, the lack of a heavy rail network in many areas creates a need for an additional 339,464 vehicles. In total, the weaker rail systems in the Outer Boroughs of New York City create the need for more than 605,000 vehicles for city households, or roughly 30-34 percent of the private vehicles registered in New York City. This is based on the assumption that a household adds only one vehicle if outside the rail network. The potential exists to add two and three cars in some areas. Clearly, the location and development of further rail transit networks will have significant impacts on car ownership, even in a dense city like New York City.

\section{Conclusions}

Figure 7 shows the potential that LRT, both the one discussed here and other possible corridors, such as the aforementioned North Shore Light Rail, could have in terms of transit connectivity. The status quo is shown here-i.e., Staten Island as almost completely cut off from the region's rail network. A relatively simple investment would change that picture radically. Through the development of a light rail over the Bayonne Bridge, an integrated transit network would be created, joining Bayonne to Staten Island. This merger would stimulate development through the region, reduce traffic congestion and emissions, and provide ample service to both communities. This extension could be a catalyst for additional mergers or the 
completion of track plans that had been abandoned. Through minor modification or redesign, facilities can provide services interlinking communities that were once only viable to travel by private vehicles.

Based upon the data in this paper, the implied Staten Island ridership via the S89 service is 91,780 annually and via automobile is 51,480 annually, bringing a total of 143,260 annual riders to HBLR service.

This case shows that robust transit linkages have a two-way relationship with economic development. Of course, it is well known that appropriately sited and planned linkages can lead to significant economic renewal. Based on the experience of Bayonne and the HBLR, a Staten Island LRT link will likely increase commercial development and revitalize development on the North Shore of Staten Island, spurring economic development and creating access to jobs that are currently limited because of inefficient transportation options. The introduction of transit-oriented development also will improve land values in the vicinity. New York City Mayor Michael Bloomberg supports the expansion of transit access to underserved areas, as Transportation Initiative 3 of PlanNYC 2030 indicates (NYC 2011). This initiative lists the possibility of reopening the Staten Island North Shore Alignment, the abandoned rail line that runs from Arlington to the Ferry Terminal. PlanNYC also contains Initiative 4, which asks to "improve and expand bus service" (NYC 2011).

At the same time, economic development and the public/private institutions responsible for planning that development can be a key factor in determining whether useful transit investments are made or not. A mere mile separates Staten Island from Bayonne. And yet, the development and associated transport policies in the two jurisdictions are many miles apart. This institutional separation has led to an obvious, and economically wasteful, disparity in a region that is otherwise closely integrated. In that sense, the HBLR serves as a cautionary tale for other urban/suburban regions where there are close actual potential links that robust transit could serve well but that might be stymied by the artifices of political and administrative borders.

\section{Acknowledgments}

This research was supported, in part, by a grant of computer time from the City University of New York High Performance Computing Center under NSF Grants 
CNS-0855217 and CNS-0958379. Also, we thank research assistants Hyoung Suk Shim, Jacquelyn Cannizzo, and Afrona Kaziu.

\section{References}

American Public Transit Association (APTA). 2010. Public Transportation Fact Book.

Brown, J. R., and G. L. Thompson. 2009. Express bus versus rail transit: How a marriage of mode and mission affects transit performance. Transportation Research Record 2110: 45-54.

Cornell University. 2008. 2008 Projection Richmond County, NY. Program on Applied Demographics, Cornell University.

De Bruijn, H., and W. Veeneman. 2009. Decision-making for light rail. Transportation Research Part A 43: 349-359.

Fitzsimmons, N., and W. Birch. 2009. Hudson-Bergen Light Rail System and economic development on the waterfront. Transportation Research Circular E-C058, 9th National Light Rail Transit Conference: 205-214.

Hensher, D. 2007. Sustainable public transport systems: Moving towards a value for money and network-based approach and away from blind commitment. Transport Policy 14: 98-102.

Marchwinski, T., G. Spitz, and T. Adler. 1999. How the introduction of the HBLR changed the demands for the Liberty State Park-and-Ride Facility. http://www. trb.org/publications/circulars/ec058/03_05_Marchwinski.pdf.

Mees, P. 2010. Transport for Suburbia: Beyond the Automobile Age. London, UK: Earthscan.

New Jersey Transit. 2010. Hudson Bergen Light Rail. http://www.njtransit.com/ti/ ti_servlet.srv?hdnPageAction=LightRailTicketsTo\&DP $=0$.

NYC. 2011. PlanNYC 2030, City of New York.

Robins, M. E., and S. W. Jans. 2008. Land development at selected Hudson-Bergen Light Rail Stations. Alan M. Voorhees Transportation Center, report for NJ Transit.

Schumann, J. W. 2006. Rail in multimodal transit systems: Concept for improving urban mobility by increasing choices for travel and lifestyle. Transportation Research Record 1571: 208-217. 
Sungyop, K., F. Gudmundur, J. Ulfarsson, and T. Hennessy. 2007. Analysis of light rail rider travel behavior: Impacts of individual, built environment and crime characteristics of transit access. Transportation Research Part A 41: 551-522.

U.S. Census. 2000. Housing and Population Survey: Travel to Work Survey.

Port Authority of New York and New Jersey (PANYNJ). 2012. Bayonne Bridge history. http://www.panynj.gov/bridges-tunnels/bayonne-bridge-history.html.

\section{About the Authors}

Dr. CAmeron Gordon (cameron.gordon@canberra.edu.au) is an Associate Professor of Economics at the University of Canberra in Australia. He also has an ongoing research appointment with the University Transportation Research Center Region 2 in New York. He has had visiting appointments with the Centre for Transport Studies at the Imperial College (London) and the Institute for Transport and Logistics Studies with the University of Sydney.

BUKURIJe BAJRAMI (bbegai@gmail.com) is an Administrator at the CUNY High Performance Computing Center and a Research Associate and visualization specialist at the Social Policy Simulation Center. She specializes in geospatial analysis and traffic flow modeling and is currently enrolled in the Urban Affairs Graduate Program at Hunter College, CUNY. She has recently presented her work at the Transportation Research Board of the National Academies of Science.

NórA TÁborı SANTIAGo (Nora.Santiago@csi.cuny.edu) is a Geographic Information Systems Specialist at The City University of New York High Performance Computing Center, located at The College of Staten Island. In addition, she serves as a technical consultant to the Center for the Study of Staten Island and is enrolled in the Urban Affairs Graduate Program at Hunter College, CUNY. She received her B.A. in Geography from Hunter College, the City University of New York, and specializes in the spatial analysis of social and demographic measures of equity, the spatial burden of taxation, and geospatial analysis of transportation system performance.

Jonathan R. Peters (Jonathan.Peters@csi.cuny.edu) is a professor of finance in the Business Department at The College of Staten Island, CUNY and a Research Fellow at the University Transportation Research Center at The City College of New York. He is also a member of the doctoral faculty in the Ph.D. Program in Earth and Environmental Sciences at the CUNY Graduate School. He received his Ph.D. in Economics from CUNY and his master's degree in Economics from Hunter College. 